International Journal of Agriculture, Environment and Bioresearch

Vol. 06, No. 05; 2021

ISSN: $2456-8643$

\title{
PHENOTYPIC VARIABILITY OF ECONOMIC PERFORMANCE IN PLANTS OF COTTON VARIETIES
}

\author{
Orif Rakhmatullaevich Ergashev \\ Junior Researcher, Laboratory of the "Primary Seed Breeding and Seed Science of Cotton Plant, Grain and \\ Leguminous Crops", Institute of Genetics and Plant Experimental Biology, Academy of sciences of the Republic of \\ Uzbekistan ,PB-111226, Kibray district, Tashkent region, Uzbekistan \\ https://doi.org/10.35410/IJAEB.2021.5661
}

\begin{abstract}
The article reveals the results of analysis in order to select primary forms for genetic-selection research to study the high and stable phenotypic potential of economic indicators of mediumfiber cotton varieties, such as cotton weight, fiber yield and length properties per unit. According to the results of the experiment, the phenotypic potential of UzFA-713 and Kelajak varieties was higher than UzFA-703, UzFA-705, UzFA-707 and UzFA-710 varieties.

According to the fiber yield indicator, UzFA-705 and UzFA-710 varieties have a higher phenotypic potential than UzFA-703, UzFA-707, UzFA-713 and Kelajak varieties. UzFA-713 and Kelajak varieties can be recommended for use as a primary source on the weight of cotton in one stem and UzFA-705 and UzFA-710 varieties for fiber yield in genetic selection studies.
\end{abstract}

Keywords: Cotton Plant,variety, Boll, Fiber Yield And Fiber Length, Phenotype.

\section{INTRODUCTION}

It is important to select the parent forms based on of differentiating cotton varieties and thoroughly studying their characteristics, knowing exactly how they differ from each other, while maintaining the economic characteristics over the years.

The study of the phenotypic stability of genotype-enriched breeding stock in several generations of plants allows to obtain complete information about the important economic performance of these traits.

In the interpreted literature [1-6] the importance of phenotype indicators of important economic characteristics of cotton varieties and hybrids is given.

The aim of the study was to select parental forms of cotton varieties based on the study of high potential and stability in plant phenotype for three years of indicators such as cotton weight, fiber yield and fiber length in one stalk. 


\section{MATERIALS AND METHODS}

In the three-generation plants of medium-fiber cotton UzFA-703, UzFA-707, UzFA-710, UzFA713 and Kelajak in 2017-2019, economic indicators of cotton varieties such as cotton weight, fiber yield and fiber length per unit were studied.

The indicators of plant height, productivity, and the ball weight in cotton genotypes statistical analysis was performed using the Fisher [7] method $(\mathrm{P}<0.05$ and $\mathrm{P}<0.01)$.

\section{RESULTS AND DISCUSSION}

In 2017, the weight of cotton in one boll was the highest in UzFA-713 and Kelajak varieties compared to other samples, the highest in UzFA-705 and UzFA-703 varieties in terms of variability, and the lowest for Kelajak variety.

In terms of fiber yield, the highest rates were observed in varieties UzFA-710 and UzFA-705, the lowest in varieties UzFA-713. It was observed that the scale of variability is higher in UzFA-713 and UzFA-707 than in other samples.

The highest values of fiber length were identified in the varieties UzFA-703, UzFA-713 and UzFA-705, and in other forms reflected a similar appearance.

The scale of population variability was higher in Kelajak variety for this category than in other forms.

Table 1. Indicators of economic characteristics of varieties in 2017

\begin{tabular}{|c|c|c|c|c|c|c|c|c|c|c|}
\hline \multirow[t]{3}{*}{ № } & \multicolumn{10}{|c|}{ Economic indicators } \\
\hline & \multirow{2}{*}{ Varieties } & \multicolumn{3}{|c|}{ cotton boll weight, gr } & \multicolumn{3}{|c|}{ Fiber yield, \% } & \multicolumn{3}{|c|}{ Fiber length, mm } \\
\hline & & $\begin{array}{l}\text { Mean } \pm \\
\text { SE }\end{array}$ & SD & V & $\begin{array}{l}\text { Mean } \pm \\
\text { SE }\end{array}$ & SD & V & $\begin{array}{l}\text { Mean } \pm \\
\text { SE }\end{array}$ & SD & $\mathrm{V}$ \\
\hline 1 & UzFA-703 & $\begin{array}{l}5,76 \pm 0.1 \\
2\end{array}$ & 0.81 & $\begin{array}{l}14.0 \\
2\end{array}$ & $\begin{array}{l}39.7 \pm 0,3 \\
8\end{array}$ & 2.53 & 6.35 & $\begin{array}{l}34.2 \pm 0.0 \\
9\end{array}$ & 0.60 & $\begin{array}{l}1.7 \\
6\end{array}$ \\
\hline 2 & UzFA -705 & $\begin{array}{l}4.89 \pm 0.1 \\
1\end{array}$ & 0.75 & $\begin{array}{l}15.3 \\
8\end{array}$ & $\begin{array}{l}42.4 \pm 0,6 \\
3\end{array}$ & 4.20 & 9.90 & $\begin{array}{l}34.0 \pm 0.0 \\
9\end{array}$ & 0.58 & $\begin{array}{l}1.7 \\
0\end{array}$ \\
\hline 3 & UzFA -707 & $\begin{array}{l}5.62 \pm 0.1 \\
0\end{array}$ & 0.68 & $\begin{array}{l}12.0 \\
2\end{array}$ & $\begin{array}{l}38.2 \pm 0,7 \\
3\end{array}$ & 4.87 & 12.7 & $\begin{array}{l}33.7 \pm 0.0 \\
9\end{array}$ & 0.57 & $\begin{array}{l}1.6 \\
8\end{array}$ \\
\hline 4 & UzFA -710 & $\begin{array}{l}5.01 \pm 0.1 \\
0\end{array}$ & 0.63 & $\begin{array}{l}12.6 \\
0\end{array}$ & $\begin{array}{l}42.7 \pm 0,4 \\
6\end{array}$ & 3.08 & 7.19 & $\begin{array}{l}33.7 \pm 0.0 \\
8\end{array}$ & 0.50 & $\begin{array}{l}1.4 \\
9\end{array}$ \\
\hline 5 & UzFA -713 & $\begin{array}{l}6.12 \pm 0.1 \\
1\end{array}$ & 0.74 & $\begin{array}{l}12.0 \\
7\end{array}$ & $\begin{array}{l}36.8 \pm 0,8 \\
9\end{array}$ & 5.87 & 15.9 & $\begin{array}{l}34.2 \pm 0.0 \\
9\end{array}$ & 0.57 & $\begin{array}{l}1.6 \\
7\end{array}$ \\
\hline 6 & Kelajak & $\begin{array}{l}5.91 \pm 0.1 \\
0\end{array}$ & 0.67 & $\begin{array}{l}11.3 \\
8\end{array}$ & $\begin{array}{l}41.4 \pm 0,7 \\
4\end{array}$ & 4.89 & 11.8 & $\begin{array}{l}33.4 \pm 0.1 \\
1\end{array}$ & 0.76 & $\begin{array}{l}2.2 \\
8\end{array}$ \\
\hline
\end{tabular}

In 2018, the weight of cotton in one boll was the highest in the Kelajak variety and the lowest in the UzFA-710 variety, while in other forms it was close to each other.

The scale of variability was higher in UzFA-705 and UzFA-703 than in other samples, and it was lower in Kelajak variety. 
The highest fiber yield was observed in UzFA-710 and UzFA-705 varieties, and the scale of population variability on this trait was phenotypically expressed in UzFA-707 and Kelajak varieties.

In terms of fiber length, UzFA-703 and UzFA-705 were the lowest, with almost the same data in all other samples. The scale of variability was higher in Kelajak and UzFA-705 varieties than in other samples.

Table 2. Indicators of economic characteristics of varieties in 2018

\begin{tabular}{|c|c|c|c|c|c|c|c|c|c|c|}
\hline \multirow[t]{3}{*}{ № } & \multicolumn{10}{|c|}{ Economic indicators } \\
\hline & \multirow[t]{2}{*}{ Varieties } & \multicolumn{3}{|c|}{$\begin{array}{l}\text { cotton weight per unit, } \\
\text { gr }\end{array}$} & \multicolumn{3}{|c|}{ Fiber yield, \% } & \multicolumn{3}{|c|}{ Fiber length, MM } \\
\hline & & $\begin{array}{l}\text { Mean } \pm \\
\text { SE }\end{array}$ & SD & $\mathrm{V}$ & $\begin{array}{l}\text { Mean } \pm \\
\text { SE }\end{array}$ & SD & $\mathrm{V}$ & $\begin{array}{l}\text { Mean } \pm \\
\text { SE }\end{array}$ & SD & $\mathrm{V}$ \\
\hline 1 & UzFA703 & $\begin{array}{l}5,24 \pm 0.1 \\
3\end{array}$ & 0.87 & $\begin{array}{l}16.6 \\
8\end{array}$ & $\begin{array}{l}36.5 \pm 0,4 \\
5\end{array}$ & 2.98 & 8.15 & $\begin{array}{l}33.7 \pm 0.1 \\
4\end{array}$ & 0.91 & $\begin{array}{l}2.7 \\
0\end{array}$ \\
\hline 2 & UzFA -705 & \begin{tabular}{|l|}
$5.02 \pm 0.5$ \\
9 \\
\end{tabular} & 3.89 & $\begin{array}{l}77.5 \\
5\end{array}$ & $\begin{array}{l}41.0 \pm 0,4 \\
6\end{array}$ & 3.08 & 7.50 & $\begin{array}{l}33.6 \pm 0.1 \\
5\end{array}$ & 1.02 & $\begin{array}{l}3.0 \\
3\end{array}$ \\
\hline 3 & UzFA -707 & \begin{tabular}{|l|}
$5.12 \pm 0.1$ \\
2 \\
\end{tabular} & 0.77 & $\begin{array}{l}15.1 \\
3 \\
\end{array}$ & $\begin{array}{l}34.8 \pm 0,7 \\
4\end{array}$ & 4.88 & 14.0 & $\begin{array}{l}34.1 \pm 0.1 \\
3\end{array}$ & 0.87 & $\begin{array}{l}2.5 \\
5 \\
\end{array}$ \\
\hline 4 & UzFA -710 & \begin{tabular}{|l|}
$4.59 \pm 0.1$ \\
1
\end{tabular} & 0.73 & $\begin{array}{l}15.7 \\
9\end{array}$ & $\begin{array}{l}41.8 \pm 0,3 \\
8\end{array}$ & 2.50 & 5.97 & $\begin{array}{l}34.4 \pm 0.1 \\
1\end{array}$ & 0.75 & $\begin{array}{l}2.1 \\
9\end{array}$ \\
\hline 5 & UzFA -713 & $\begin{array}{l}5.40 \pm 0.1 \\
1\end{array}$ & 0.72 & $\begin{array}{l}14.0 \\
7\end{array}$ & $\begin{array}{l}37.0 \pm 0,4 \\
4\end{array}$ & 2.93 & 7.91 & $\begin{array}{l}34.9 \pm 0.1 \\
0\end{array}$ & 0.65 & $\begin{array}{l}1.8 \\
7\end{array}$ \\
\hline 6 & Kelajak & \begin{tabular}{|l|}
$6.38 \pm 0.1$ \\
2 \\
\end{tabular} & 0.81 & $\begin{array}{l}12.6 \\
3\end{array}$ & $\begin{array}{l}38.3 \pm 0,7 \\
9\end{array}$ & 5.26 & 13.7 & $\begin{array}{l}34.3 \pm 0.2 \\
3\end{array}$ & 1.52 & $\begin{array}{l}4.4 \\
1 \\
\end{array}$ \\
\hline
\end{tabular}

In 2019, the weight of cotton in one boll is the same as in 2018, with the highest in the Kelajak variety and the lowest in the UzFA-710 variety, while in other forms it was close to each other. The scale of variability was higher in UzFA-703 and UzFA-710 compared to other hybrid varieties, and it was the lowest in Kelajak variety.

The highest fiber yield was observed in varieties UzFA-710 and UzFA-703, and the scale of variability of the population on this trait was found to be higher in varieties UzFA-705 and UzFA-707 than other samples.

The fiber length of UzFA-713, UzFA-705, UzFA-707 and UzFA-710 were very close to each other, and UzFA-703 had the lowest data.

The scale of variability was higher in Kelajak, UzFA-710 and UzFA-703 varieties than in other samples.

Table 3. Indicators of economic characteristics of varieties in 2019

\begin{tabular}{|l|l}
\hline № & Economic indicators \\
\hline
\end{tabular} 
Vol. 06, No. 05; 2021

ISSN: $2456-8643$

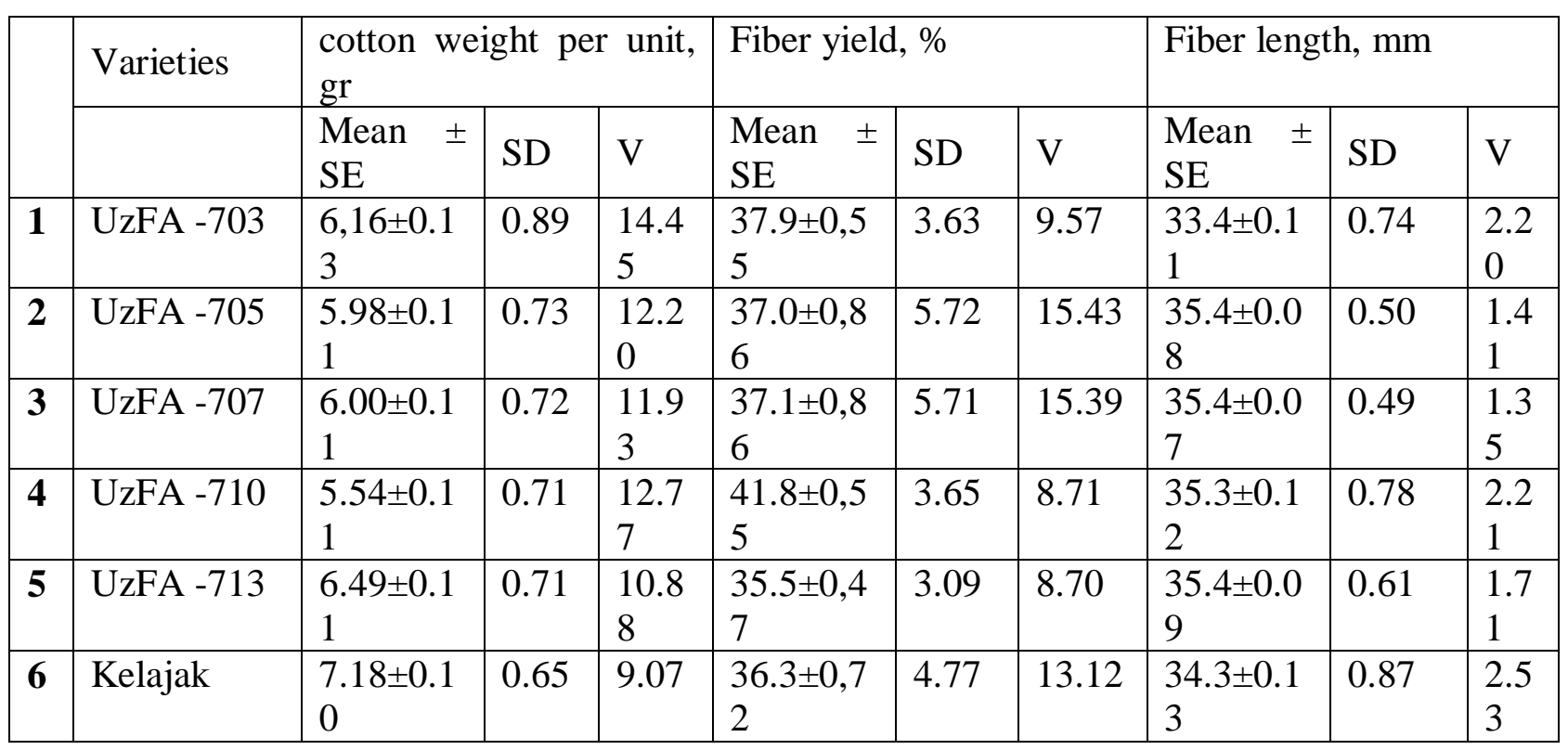

According to the general average performance of the three generations of plants, the weight of cotton in one stem is high in Kelajak and UzFA-713, fiber yield in UzFA-710 and UzFA-705, fiber length in UzFA-713, UzFA-710, UzFA-707 and UzFA-705 varieties were found to have close data to each other.

The variability of the indicators was observed in the UzFA-705 variety in terms of cotton weight per unit, in the UzFA-707 variety in terms of fiber yield and in the Kelajak variety in terms of fiber length qualities compared to other items.

Table 4. Overall average indicators in 2017-2019

\begin{tabular}{|c|c|c|c|c|c|c|c|c|c|c|}
\hline \multirow[t]{3}{*}{ № } & \multicolumn{10}{|c|}{ Economic indicators } \\
\hline & \multirow[t]{2}{*}{ Varieties } & \multicolumn{3}{|c|}{$\begin{array}{l}\text { cotton weight per unit, } \\
\text { gr }\end{array}$} & \multicolumn{3}{|c|}{ Fiber yield, \% } & \multicolumn{3}{|c|}{ Fiber length, mm } \\
\hline & & $\begin{array}{l}\text { Mean } \pm \\
\text { SE }\end{array}$ & SD & $\mathrm{V}$ & $\begin{array}{l}\text { Mean } \pm \\
\text { SE }\end{array}$ & SD & V & $\begin{array}{l}\text { Mean } \pm \\
\text { SE }\end{array}$ & SD & $\mathrm{V}$ \\
\hline 1 & UzFA -703 & \begin{tabular}{|l|}
$5,72 \pm 0.1$ \\
2
\end{tabular} & 0.85 & $\begin{array}{l}15.0 \\
5\end{array}$ & $\begin{array}{l}37.4 \pm 0,4 \\
6\end{array}$ & 3.04 & 8.02 & $\begin{array}{l}33.7 \pm 0.1 \\
1\end{array}$ & 0.75 & $\begin{array}{l}2.2 \\
2\end{array}$ \\
\hline 2 & UzFA -705 & \begin{tabular}{|l}
$5.29 \pm 0.2$ \\
7
\end{tabular} & 1.79 & $\begin{array}{l}35.0 \\
4\end{array}$ & $\begin{array}{l}40.1 \pm 0,6 \\
5\end{array}$ & 4.33 & 10.94 & $\begin{array}{l}34.3 \pm 0.1 \\
0\end{array}$ & 0.7 & $\begin{array}{l}2.0 \\
2\end{array}$ \\
\hline 3 & UzFA -707 & \begin{tabular}{|l|}
$5.58 \pm 0.1$ \\
1
\end{tabular} & 0.72 & $\begin{array}{l}13.0 \\
0\end{array}$ & $\begin{array}{l}36.7 \pm 0,7 \\
7\end{array}$ & 5.15 & 14.0 & $\begin{array}{l}34.4 \pm 0.0 \\
9\end{array}$ & 0.64 & $\begin{array}{l}1.8 \\
6\end{array}$ \\
\hline 4 & $\mathrm{UzF} A$ & \begin{tabular}{|l}
$5.04 \pm 0.1$ \\
0
\end{tabular} & 0.69 & $\begin{array}{l}13.7 \\
2\end{array}$ & $\begin{array}{l}42.1 \pm 0,4 \\
6\end{array}$ & 3.07 & 7.29 & $\begin{array}{l}34.4 \pm 0.1 \\
0\end{array}$ & 0.67 & $\begin{array}{l}1.9 \\
6\end{array}$ \\
\hline 5 & UzFA -713 & \begin{tabular}{|l|}
$6.00 \pm 0.1$ \\
1
\end{tabular} & 0.72 & $\begin{array}{l}12.3 \\
4\end{array}$ & $36.4 \pm 0,6$ & 3.96 & 10.8 & $\begin{array}{l}34.8 \pm 0.0 \\
9\end{array}$ & 0.61 & $\begin{array}{l}1.7 \\
5\end{array}$ \\
\hline 6 & Kelajak & $6.49 \pm 0.1$ & 0.71 & 11.0 & $38.6 \pm 0,7$ & 4.97 & 12.87 & $34.0 \pm 0.1$ & 1.05 & 3.0 \\
\hline
\end{tabular}




\begin{tabular}{|l|l|l|l|l|l|l|l|l|}
\hline & 0 & 2 & 5 & & & 5 & & 7 \\
\hline
\end{tabular}

\section{CONCLUSIONS}

As a result of the experiment, it can be said that the phenotypic potential of UzFA-713 and Kelajak varieties was higher than UzFA-703, UzFA-705, UzFA-707 and UzFA-710 varieties. According to the indicator of fiber yield, UzFA-705 and UzFA-710 varieties have higher phenotypic potential than UzFA-703, UzFA-707, UzFA-713 and Kelajak varieties. Different levels of variability were observed in the varieties according to the indicator of fiber length properties. Varieties with the above-mentioned phenotypic potential may be recommended for use in these genetic-selection studies as a primary form of these cotton varieties.

\section{REFERENCES:}

Egamberdiev R.R., Avtonomov vikA., Kimsanbaev M.Kh. "Variability and heritability of fiber yield in geographically distant hybrids $F_{1}-F_{2}$ of cotton// "Cotton, alfalfa selection and seed production" scientific research collection. Tashkent-2009. FAN, 213-218 p.

Ya. Babaev., G.Orazbaeva., M.Mirahmedov., R. Birgieva "Indicators of valuable traits in medium-fiber cotton varieties". AGRO ILM - Journal of Agriculture of Uzbekistan 2019, №.3, 12-13 p.

Yuldasheva T.A. Amanturdiev I.G. "Formation and variability of fiber yield in high- generation hybrids of cotton plant". "Modern problems of genetics, genomics and biotechnology" Proceedings of the Republican scientific- practical conference. 2017, $121 \mathrm{p}$.

Kahharov I.T., Ergashev O.R., Hakimov A.E. "New variety- new features". Journal AGRO ILM, №-4[48], 2017. 8-9 p.

Kahharov I.T., Ergashev O.R., Dadajanov J.R., Hakimov A.E., Kogirova M.R. "new cotton variety UzFA-707 and its characteristics". Journal AGRO ILM, No. 3[47], 2017. 10-11 p.

Khamidullaev Sh.A., Nabiev S.M., Abdushukurova S.K., Shavkiev K.Sh. "Inheritance of a single- pod cotton weight mark in $\digamma_{1}$ hybrids of G.hirsutum L." - "Modern problems of genetics, genomics and biotechnology" Proceedings of the Republican scientific- practical conference 2017, 115-116 p.

Fisher RA. Statistical Methods for Research Workers (4th Ed.). Edinburgh:Oliver \& Boyd; 1934. 